Portland State University

PDXScholar

\title{
Delayed Switch of Antiretroviral Therapy after Virologic Failure Associated with Elevated Mortality among HIV-infected Adults in Africa
}

\author{
Maya L. Petersen \\ University of California, Berkeley \\ Linh Tran \\ University of California, Berkeley \\ Elvin H. Geng \\ University of California, San Francisco \\ Steven J. Reynolds \\ Rakai Health Sciences Program, Entebbe, Uganda \\ Andrew Kambugu \\ Infectious Diseases Institute Kampala, Uganda \\ Follow this and additional works at: https.//pdxscholar.library.pdx.edu/sph_facpub \\ Part of the Immune System Diseases Commons, Infectious Disease Commons, and the Virus \\ Serenextspage for âdditional authors \\ Let us know how access to this document benefits you.
}

\section{Citation Details}

257. Petersen ML, Tran L, Geng EH, Reynolds SJ, Kambugu A, Wood R, Bangsberg DR, Yiannoutsos CT, Deeks SG, Martin JN. Delayed switch of antiretroviral therapy after virologic failure associated with elevated mortality among HIV-infected adults in Africa. AIDS. 2014 Jun 28. [Epub ahead of print] PubMed PMID: 24977440

This Post-Print is brought to you for free and open access. It has been accepted for inclusion in OHSU-PSU School of Public Health Faculty Publications and Presentations by an authorized administrator of PDXScholar. Please contact us if we can make this document more accessible: pdxscholar@pdx.edu. 


\section{Authors}

Maya L. Petersen, Linh Tran, Elvin H. Geng, Steven J. Reynolds, Andrew Kambugu, Robin Wood, David Bangsberg, Constantin T. Yiannoutsos, Steven G. Deeks, and Jeffrey N. Martin 


\section{Abstract}

Objective-Routine monitoring of plasma HIV RNA among HIV-infected patients on antiretroviral therapy (ART) is unavailable in many resource-limited settings. Alternative monitoring approaches correlate poorly with virologic failure and can substantially delay switch to second-line therapy. We evaluated the impact of delayed switch on mortality among patients with virologic failure in Africa.

Design-A cohort.

Methods-We examined patients with confirmed virologic failure on first-line non-nucleoside reverse transcriptase inhibitor (NNRTI)-based regimens from four cohorts with serial HIV RNA monitoring in Uganda and South Africa. Marginal structural models aimed to estimate the effect of delayed switch on mortality in a hypothetical trial in which switch time was randomly assigned. Inverse probability weights adjusted for measured confounders including time-updated $\mathrm{CD} 4^{+} \mathrm{T}$ cell count and HIV RNA.

Results-Among 823 patients with confirmed virologic failure, the cumulative incidence of switch 180 days after failure was 30\% [95\% confidence interval (CI) 27-33]. The majority of patients $(74 \%)$ had not failed immunologically as defined by WHO criteria by the time of virologic failure. Adjusted mortality was higher for individuals who remained on first-line therapy

(C) 2014 Wolters Kluwer Health | Lippincott Williams \& Wilkins

Correspondence to Maya L. Petersen, University of California, Berkeley, 101 Haviland Hall, Berkeley, CA 94720-7358, USA, Tel: +1 510642 0563, fax: +1 510643 5163, mayaliv@ berkeley.edu.

Conflicts of interest: There are no conflicts of interest. 
than for those who had switched [odds ratio (OR) 2.1, 95\% CI 1.1 -4.2]. Among those without immunologic failure, the relative harm of failure to switch was similar (OR 2.4; 95\% CI 0.99-5.8) to that of the entire cohort, although of borderline statistical significance.

Conclusion-Among HIV-infected patients with confirmed virologic failure on first-line ART, remaining on first-line therapy led to an increase in mortality relative to switching. Our results suggest that detection and response to confirmed virologic failure could decrease mortality.

\section{Keywords}

antiretroviral; cohort studies; HIV; HIV RNA level; inverse probability weight; marginal structural model; time-dependent confounding; treatment failure; viral load

\section{Introduction}

First-line nonnucleoside reverse transcriptase inhibitor (NNRTI)-based regimens save the lives of millions of HIV-infected patients globally; however, resistance to these regimens results in increased viral replication (virologic failure). In resource-rich settings, HIV RNA levels are monitored regularly and the threshold to switch regimens after virologic failure is detected is low [1]. However, in Africa, delayed switch following failure is common due to several factors. First, routine plasma HIV RNA monitoring is often unavailable and alternative $\mathrm{CD}^{+}{ }^{+} \mathrm{T}$-cell and clinical criteria provide poor surrogates [2-7]. Second, until recently, WHO guidelines suggested that HIV RNA levels below 5000 or 10000 copies $/ \mathrm{ml}$ did not warrant immediate regimen switch [8,9]. Third, second-line regimens are expensive, and in the absence of compelling data that switching immediately is needed, the resources to fund such regimens have been limited. Finally, when patients have confirmed HIV RNA rebound, clinicians may be hesitant to switch patients with perceived poor adherence.

Although delayed switch following virologic failure exposes patients to accumulation of resistance mutations and advanced immunosuppression, the clinical effect of delayed switch in resource-limited settings has not been adequately quantified [10-13]. To date, four randomized trials found no significant reduction in mortality among individuals monitored with routine HIV RNA compared to those with access to clinical monitoring only, $\mathrm{CD} 4^{+}$and clinical monitoring, or $\mathrm{CD}^{+}$and clinical monitoring with discretionary HIV RNA levels [14-18]. However, the excellent adherence and limited follow-up time in these studies, and thus few virologic failures and deaths, resulted in attenuated power.

There are several lines of indirect evidence that routine HIV RNA monitoring and prompt switching are important. In multisite observational studies in southern Africa, patients treated in programmes with routine HIV RNA monitoring had higher switch rates, higher $\mathrm{CD} 4^{+} \mathrm{T}$-cell counts at switch and lower mortality than patients treated in programmes without routine HIV RNA levels [19,20]; however, clinics with HIV RNA testing may have had additional resources or infrastructure, confounding observed associations. Delayed switch following failure has been associated with lower rates of virologic suppression on second-line therapy in South Africa; however, prior analyses did not quantify mortality impact nor did they adjust for confounding by time-updated $\mathrm{CD} 4^{+}$cell count, HIV RNA level or other factors [21]. 
In order to evaluate the impact of delayed switch to second-line therapy following confirmed virologic failure on mortality in Africa, we used data from adult patients treated with firstline NNRTI-based antiretroviral therapy (ART) in four African clinics where serial HIV RNA monitoring was carried out. We analysed a large number of patients with confirmed virologic failure treated in routine care settings and controlled in analysis for clinic. Finally, we used inverse probability weights to adjust for confounding by time-varying $\mathrm{CD} 4^{+} \mathrm{T}$-cell count and plasma HIV RNA level, factors that are affected by prior antiretroviral treatment and thus not amenable to traditional regression-based adjustment [22].

\section{Materials and methods}

\section{Patient population}

We examined data from HIV-infected adults who initiated first-line NNRTI-based ART between 2002 and 2011 in one of four prospective cohorts: Uganda AIDS Rural Treatment Outcomes (UARTO), a research cohort in Mbarara, Uganda; Infectious Diseases Institute (IDI), a research cohort in Kampala, Uganda; Rakai Health Sciences Program (RHSP), a clinic-based cohort in Rakai, Uganda; and, Gugulethu, a clinic-based cohort in Cape Town, South Africa. At the time of analysis, UARTO included 484 ART initiators, RHSP included 1665 initiators, IDI included 559 initiators and Gugulethu included 5267 initiators. Patients followed in these cohorts were managed by clinics that followed concurrent WHO guidelines. All cohorts serially measured plasma HIV RNA level.

\section{Measurements}

Patients who experienced confirmed virologic failure while on first-line NNRTI-based ARTwere included in primary analyses. Virologic failure could occur any time at least 16 weeks after ART initiation and was defined as two consecutive 'failing' HIV RNA levels measured fewer than 270 days apart. HIV RNA levels measured between 12 and 24 weeks after ART initiation were classified as 'failing' if they were more than 1000 copies/ml; HIV RNA levels measured after 24 weeks of ART were classified as failing if they were more than 400 copies/ml [11]. In sensitivity analyses, we analysed patients with confirmed rebound (confirmed virologic failure with at least one prior HIV RNA level $<400$ copies/ml) and unconfirmed rebound (a single HIV RNA level $\geq 400$ copies $/ \mathrm{ml}$ with at least one prior HIV RNA level <400copies/ml).

Secondary analyses evaluated patients without immunological failure prior to or concurrent with virologic failure. Immunologic failure was defined as meeting either of the WHO 2013 criteria: $\mathrm{CD} 4^{+}$cell count less than or equal to pretherapy baseline or $\mathrm{CD} 4^{+}$cell count less than 100 cells/ $\mu$ after at least 6 months of ART [9]. In addition to serial HIV RNA and $\mathrm{CD} 4{ }^{+}$cell count measurements, all cohorts recorded age, sex and clinical stage at ART initiation. Switch to second-line therapy was defined as initiation of a protease inhibitor (boosted lopinavir). Deaths were ascertained via linkage to a national death registry (Gugulethu) or active tracking in the community (the East African cohorts). 


\section{Ethics}

The study was approved by all appropriate local and national Institutional Review Boards. Analyses were conducted with de-identified data.

\section{Analysis}

Time zero was defined as date of virologic failure confirmation. Cumulative incidence of switch to second-line therapy following confirmed virologic failure was estimated treating death as a competing event [23,24]. For remaining analyses, data were discretized into 30day intervals, with time-varying variables coded as the most recent measurement available to guide clinical decision-making at the start of an interval. Unadjusted associations of each potential confounder with mortality and switch were calculated using pooled logistic regression models with robust standard error estimates to account for repeated measures [25].

Marginal structural models were used to investigate how delayed switch to second-line therapy impacted mortality over time. Analyses targeted a hypothetical trial in which individuals were enrolled at the time of confirmed failure and were assigned a random switch time, ranging from switch immediately (first 30 days following confirmation of failure) to never switch. Marginal structural models were used to summarize how use of first versus second-line therapy (switch status) at the end of an interval affected probability of dying in the following interval $[11,22,26]$. We fit pooled logistic regression models that included time since failure and switch status as main terms, as well as models with an additional interaction term between time and switch status and models with a natural cubic spline on time with knots at the 25th, 50th, and 75th percentiles.

Several time-varying variables, including $\mathrm{CD}^{+}{ }^{+}$cell count, HIV RNA and clinic visit frequency, influence decisions whether and when to switch therapy, as well as affecting mortality; thus adjustment for confounding by these variables is needed. These same variables, however, are affected by prior switching decisions and mediate the effect of exposure to failing first-line therapy on mortality. Hence, adjustment via standard regression will bias results $[11,22,26]$. Inverse probability weighting (IPW) was therefore used to adjust for measured confounders [22,27].

In primary analyses, individuals were censored at reported transfer to an outside clinic or database closure, an appropriate approach under the assumptions of complete death ascertainment and transfer reporting. In secondary analyses, we relaxed this assumption by censoring at the first of database closure, transfer or 270 days without a recorded visit or laboratory test, with 270 chosen to reflect at least two consecutive missed visits and to reduce censoring of patients with a missed visit who subsequently returned to care. An additional weight was used to adjust for measured sources of potentially informative censoring, with separate components for each cause of censoring.

All treatment and censoring weights were estimated using Super Learner, a data adaptive approach that used 10-fold cross-validation to learn the optimal weighted combination of a library of algorithms [28]. The library included multivariate adaptive polynomial spline regression combined with initial screening to limit adjustment variables to those either 
associated with mortality $(P<0.2)$ or considered a priori to be important confounders $\left(\mathrm{CD}^{+}\right.$cell count, HIV RNA level and clinic), as well as five candidate parametric logistic regression models a priori specified on the basis of background knowledge [29-31]. The set of candidate confounders included clinic, age, sex, baseline WHO stage, calendar date of failure, virologic suppression prior to failure, $\mathrm{CD} 4^{+}$cell count and HIV RNA level at the time of failure and a range of time-varying summaries (including nadirs, zeniths and change over time) of $\mathrm{CD}^{+}{ }^{+}$cell count, HIV RNA level and recorded visit frequency (Table 2 ). In sensitivity analysis, we excluded WHO stage at ART initiation from the adjustment set.

All weights were stabilized [22]. Standard errors were estimated using the robust sandwich estimator [25].

\section{Results}

Among 7975 patients on first-line NNRTI-based ART, 823 patients experienced confirmed virologic failure. Among these patients, $52 \%$ of first-line regimens contained efavirenz and $48 \%$ contained nevirapine. Of the 358 patients who had their therapy switched to secondline protease inhibitor based ART, the median time to switch was 116 days after confirmation of failure [interquartile range (IQR) 63-198 days]. Cumulative incidence of switch by 30, 90 and 180 days after failure was 3\% [95\% confidence interval (CI) 2-4], 16\% (95\% CI 14-19) and 30\% (95\% CI 27-33), respectively (Fig. 1a). Most patients (74\%) had not failed immunologically (as defined by WHO criteria) by the time of virologic failure; 140 individuals (17\% of failures) experienced at least one HIV RNA level less than 400 copies/ml after confirmed failure and while still on first-line therapy.

Among 823 patients with confirmed failure, a median of 79 days passed between first and confirmatory failing HIV RNA levels (IQR 53-115 days). The confirmatory failing HIV RNA measurement occurred a median of 1.4 years after ART initiation (IQR 0.8-2.6 years). Median values at the time of failure were $220 \mathrm{CD}^{+}{ }^{+} \mathrm{T}$ cells $/ \mu \mathrm{l}$ and 6214 plasma HIV RNA copies/ml; 197 (24\%) of individuals with confirmed virologic failure had not previously suppressed HIV RNA level below 400 copies/ml (Table 1).

\section{Predictors of switch and mortality}

In unadjusted analyses, switch to second-line therapy was associated with lower $\mathrm{CD} 4^{+}$cell count at treatment initiation and most recent measurement, lower nadir and peak $\mathrm{CD}^{+}{ }^{+}$cell counts (including $\mathrm{CD} 4^{+}$cell count prior to ART initiation), greater percentage decline in $\mathrm{CD}^{+}$cell count since failure, higher HIV RNA level at most recent measurement, higher nadir HIV RNA level, baseline WHO clinical stage III or IV, and shorter duration between ART start and virologic failure (Table 2).

We observed 49 deaths among 823 persons, followed for a median of 2.1 years after failure (2.5 deaths per 100 person-years, Fig. 1b); 32 deaths (65\%) occurred while still on first-line ART. Median CD4 ${ }^{+}$cell count at death was 107 cells/ $\mu$ (IQR 46-211 cells/ $\mu l$ ), measured a median of 90 days before death (IQR 34-136 days). Of the 17 deaths after switch, 14 had an HIV RNA level measured after switch. Of these, last measured HIV RNA level, measured a median of 134 days before death (IQR 72-205 days), was less than 400 copies/ml for four 
patients and less than 1000 copies/ml for seven patients. In unadjusted analyses, significant predictors of mortality included lower $\mathrm{CD} 4^{+}$cell count at the most recent measurement, lower nadir $\mathrm{CD}^{+}$cell count, greater percentage decline in $\mathrm{CD}^{+}$cell count since failure, higher HIV RNA level at the most recent measurement and at the time of failure, higher nadir and peak HIV RNA level, older age, male sex and recorded visit within prior 90 days (Table 2).

Before adjustment for confounding, the discrete hazard of death was not significantly different among patients who remained on first-line therapy compared with patients who had switched. Assuming a constant relative odds over time, the relative odds of death among individuals on first-line therapy was $1.5(95 \% \mathrm{CI} 0.8,2.6)$ compared with those on secondline. When an interaction term between switching status and time was included, remaining on first-line therapy was associated with elevated mortality, although the magnitude of this association declined nonsignificantly over time (Table 3).

\section{Estimated effect of delayed switch}

Adjustment for measured confounders increased the estimated magnitude of harm due to delayed switch (Table 3). Assuming a constant relative odds over time, the adjusted relative odds of death among individuals still on first-line therapy compared with those who had switched was 2.1 (95\% CI 1.1-4.2). When an interaction term between switching status and time was included, for the first 28 months following failure those individuals who remained on first-line therapy had a higher probability of dying than those who had switched; the protective effect of switch declined nonsignificantly over time since failure $(P=0.09)$ (Table 3, Fig. 2a). Exclusion of the 197 patients without at least one HIV RNA level less than 400 copies/ml prior to failure resulted in similar estimates (Table 3). Inclusion of time since failure as a restricted cubic spline and exclusion of baseline stage from the adjustment set had a minimal impact on all estimates (data not shown).

The majority of patients (74\%) had not failed immunologically (as defined by WHO criteria) by the time of virologic failure. Median $\mathrm{CD}^{+}$cell count among these 610 patients at virologic failure was 258 cells/ $\mu$ (IQR $179-340$ cells/ $\mu$ l). Among the 293 who subsequently switched, median CD4+ $4^{+}$cell count at switch was 253 cells/ $\mu$ (IQR: $168-328$ cells $/ \mu l$ ).

Seventy-one of these patients subsequently failed immunologically and 27 died. Among the 15 patients who died on first-line therapy, median $\mathrm{CD}^{+}$cell count at death was 107 cells/ $\mu \mathrm{l}$ (IQR 48-209 cells/ $\mu \mathrm{l}$ ), measured a median of 90 days before death. Among the 12 patients who died on second-line therapy, median $\mathrm{CD}^{+}$cell count at death was 124 cells/ $\mu \mathrm{l}$ (IQR 35-264 cells/ $\mu \mathrm{l}$ ), measured a median of 183 days before death. After adjustment for measured confounders of switch, estimated mortality in this subpopulation was lower than in the full cohort (Fig. 2b). Assuming a constant relative odds over time, the adjusted relative odds of death among individuals still on first-line therapy compared to those who had switched was 2.4 (95\% CI 0.99-5.8), similar to that of the full cohort, although of borderline significance $(P=0.052)$ (Table 3$)$.

Three hundred and fifty-one (43\%) patients experienced at least one episode of 270 days or more without a recorded visit, a median of 510 days after virologic failure (IQR 300-855 days). Using this definition of 'loss to follow up', 39 deaths prior to loss, transfer or 
database closure were observed. The estimated effect of delayed switch was similar to estimates that censored only at database closure or reported transfer (Table 3).

Nonconfirmed virologic rebound, defined as a single HIV RNA level of at least 400 copies/ml with at least one preceding HIV RNA level less than 400 copies/ml, was observed in 1337 patients. Of these, 1153 (86\%) had at least one subsequent HIV RNA level measured on first-line therapy, measured a median of 84 days after initial unsuppressed HIV RNA level (IQR 56-126 days). The majority (55\%) of these confirmatory RNA levels were less than 400 copies $/ \mathrm{ml}$. Among individuals with nonconfirmed rebound, in both unadjusted and adjusted analyses mortality was no higher among individuals who remained on first-line therapy than among those on second-line (Table 3).

\section{Discussion}

When to switch therapy for treatment 'failure' in resource-poor regions remains controversial. Much of the debate has been informed by cost concerns and practical issues, as well as by several randomized clinical studies in which most patients did well and followup time was limited (median 1.5-3 years following ART initiation), making it hard to evaluate clinical outcomes among the small numbers of failures [14-18]. In this study, we identified a large number of individuals with confirmed virologic failure in routine clinical practice, followed for a median of 4.3 years after ART initiation (2.2 years after confirmed failure). We found that switching to second-line protease inhibitor based therapy was delayed in many patients, a practice that others have found to be common, even in settings in which routine HIV RNA monitoring and second-line therapy are available [32-35]. We found, after adjustment for measured confounders, that remaining on first-line therapy following confirmed virologic failure significantly increased mortality. The estimated effect of delayed switch was similar among individuals without evidence of immunologic failure at the time of virologic failure, although of borderline statistical significance.

Several factors may have contributed to delayed switch in our study cohorts. First, clinician access to HIV RNA results was likely delayed in many cases, particularly in cohorts in which HIV RNA levels were drawn for research purposes. Second, during much of the study period, the WHO recommended an HIV RNA threshold of 5000 or 10000 copies $/ \mathrm{ml}$, ideally with confirmation, for switching [8,9]. Third, clinicians may have delayed switch in patients with perceived adherence lapses or with tuberculosis treated with rifampicin due to concern for pharmacological interactions with ritonavir, or may have prioritized use of costly and scarcer second-line drugs for patients deemed most likely to benefit. Fourth, initiation of second-line therapy may have required scheduling and attendance at a subsequent visit.

We required confirmation of failure in order to improve specificity for true virologic failures rather than 'blips' or falsely elevated HIV RNA levels due to laboratory error [36]. Among patients who achieved a suppressed HIV RNA level, the majority of initial HIV RNA measurements of at least 400 copies/ml were followed by a consecutive HIV RNA measurement of less than $400 \mathrm{copies} / \mathrm{ml}$, and we were unable to detect any effect of delayed switch on mortality among patients with nonconfirmed virologic rebound. These 
observations support the use of a confirmatory HIV RNA level for switching, at least at the lower threshold for suppression [37].

Patients in our cohort initiated ART at low $\mathrm{CD}^{+}$cell counts. This may have contributed to high mortality resulting from failure to switch. The impact of delayed switch following confirmed virologic failure may differ among patients initiating ART more recently and at higher $\mathrm{CD} 4^{+}$cell counts.

As has been observed by others, a substantial proportion of individuals with confirmed failure had at least one subsequent HIV RNA level of less than 400 copies $/ \mathrm{ml}$ while still on first-line therapy [17,34]. In the absence of resistance testing, which is unlikely to be widely available in this region, any definition of virologic failure will include some patients with transient loss of suppression. Our analyses suggest that in the absence of resistance testing, prompt switch to second-line therapy following confirmed failure has the potential to save lives.

Our estimates of the impact of delayed switch on mortality rely on measured variables to adjust for confounding. We were not able to adjust for time-updated WHO stage following ART initiation, as this measure was not introduced until 2010 and remains inconsistently applied in practice [8]. Sensitivity analyses excluding baseline WHO stage from the adjustment set had a minimal impact on estimates, suggesting that the baseline measure provides little additional confounding control after other measured covariates (including serial $\mathrm{CD} 4^{+}$cell count and HIV RNA) are adjusted for. However, unmeasured confounding by disease severity and perceived adherence not captured by $\mathrm{CD} 4^{+}$cell count and HIV RNA measures might result in either under or overestimates of the harm of delayed switch.

Nonetheless, use of inverse probability of treatment weighting rather than standard regression made it possible to adjust for measured sources of time-varying confounding and informative censoring, including serial $\mathrm{CD}^{+}$cell counts and HIV RNA levels (the latter of which correlates with adherence). We further minimized potential bias due to model misspecification through use of data-adaptive methods when estimating the weights and through use of alternative marginal structural model specifications in sensitivity analyses [28]. Further, although all cohorts had some form of active outcome ascertainment, both death ascertainment and transfer reporting may have been incomplete, resulting in bias not amenable to adjustment without supplementary data [38]. Sensitivity analyses in which patients were censored after 270 days without a clinic visit resulted, however, in similar estimates of increased mortality due to delayed switch.

We investigated the potential benefit of routine HIV RNA level monitoring compared with $\mathrm{CD} 4^{+}$cell count monitoring alone by estimating the effect of delayed switch among patients who had not met WHO immunologic failure criteria by the time of confirmed virologic failure, and thus who would not yet have been switched under $\mathrm{CD} 4^{+}$cell count criteria. Point estimates of the effect of delayed switch in these patients were similar to the larger group, but had less statistical precision. These secondary analysis are subject to several limitations, however. First, we had limited power to detect an effect in this subgroup. Second, these analyses do not directly quantify the impact of routine HIV RNA level 
monitoring, as data were not available to assess WHO clinical failure criteria, and a minority of patients subsequently failed immunologically and thus would have experienced a delayed switch with $\mathrm{CD} 4^{+}$cell count monitoring alone. Although dynamic regime methods address the latter concern, they typically require larger samples [39,40]. Third, our analyses underestimate the benefits of routine viral monitoring in that they do not account for reduction in unneeded switches due to poor specificity of immunologic failure criteria, improved opportunity for targeted adherence interventions, decreased acquired and transmitted resistance, or reduced infectivity [3,7,41-44]. Although simulation models can investigate these broader health, transmission and costing implications, such models rely on understanding the mortality impact of deferred switch following virologic failure; our analyses contribute to this knowledge base [45-49].

\section{Conclusion}

To the best of our knowledge, our study is the first to estimate the impact of delayed switch to second-line therapy following confirmed virologic failure on mortality among patients treated in a resource-limited setting, taking into account time-varying confounders of switching. Many individuals did not switch to second-line therapy following confirmation of virologic failure, or switched only after substantial delay, and these delays increased mortality relative to immediate switch. Our findings support the importance of detection and response to virologic failure.

\section{Acknowledgments}

M.P. conceived the study, planned and supervised the analysis, interpreted results and wrote the manuscript. L.T. implemented the analysis and contributed to interpretation and writing. S.D. and J.M. contributed to study conception, data collection, planning and interpretation of analyses, and writing. E.G., S.R., A.K., R.W., D.B. and C.Y. contributed to data collection, interpretation of analyses and writing.

This research was supported by grants from the National Institutes of Health, P30 AI027763, R01 MH054907 and U01 AI069911, and U01 CA066529. Maya Petersen was supported by a Doris Duke Clinical Scientist Development Award. Steven Deeks was supported by K24 AI069994. David Bangsberg was supported by K24 MH87227 Elvin Geng was supported by K23 AI084544. S.J.R. was supported in part by the Division of Intramural Research, NIAID, NIH.

\section{References}

1. Panel on Antiretroviral Guidelines for Adults and Adolescents. [Accessed 5 November 2013] Guidelines for the use of antiretroviral agents in HIV-1-infected adults and adolescents. Department of Health and Human Services. http://aidsinfo.nih.gov/ContentFiles/Adultand.AdolescentGL.pdf

2. Stringer JS, Zulu I, Levy J, Stringer EM, Mwango A, Chi BH, et al. Rapid scale-up of antiretroviral therapy at primary care sites in Zambia: feasibility and early outcomes. JAMA. 2006; 296:782-793. [PubMed: 16905784]

3. Keiser O, MacPhail P, Boulle A, Wood R, Schechter M, Dabis F, et al. Accuracy of WHO CD4 cell count criteria for virological failure of antiretroviral therapy. Trop Med Int Health. 2009; 14:12201225. [PubMed: 19624478]

4. Ingole N, Mehta P, Pazare A, Paranjpe S, Sarkate P. Performance of immunological response in predicting virological failure. AIDS Res Hum Retroviruses. 2013; 29:541-546. [PubMed: 23137294]

5. Rawizza HE, Chaplin B, Meloni ST, Eisen G, Rao T, Sankale JL, et al. Immunologic criteria are poor predictors of virologic outcome: implications for HIV treatment monitoring in resource-limited settings. Clin Infect Dis. 2011; 53:1283-1290. [PubMed: 22080121] 
6. Reynolds SJ, Nakigozi G, Newell K, Ndyanabo A, Galiwongo R, Boaz I, et al. Failure of immunologic criteria to appropriately identify antiretroviral treatment failure in Uganda. AIDS. 2009; 23:697-700. [PubMed: 19209067]

7. Westley BP, DeLong AK, Tray CS, Sophearin D, Dufort EM, Nerrienet E, et al. Prediction of treatment failure using 2010 World Health Organization Guidelines is associated with high misclassification rates and drug resistance among HIV-infected Cambodian children. Clin Infect Dis. 2012; 55:432-440. [PubMed: 22539664]

8. WHO. Antiretroviral therapy for HIV infection in adults and adolescents: recommendations for a public health approach 2010 Revision. Geneva: WHO; 2010.

9. WHO. Consolidated guidelines on the use of antiretroviral drugs for treating and preventing HIV infection: recommendations for a public health approach. Geneva: World Health Organization; 2013.

10. Hatano $\mathrm{H}$, et al. Rate of viral evolution and risk of losing future drug options in heavily pretreated, HIV-infected patients who continue to receive a stable, partially suppressive treatment regimen. Clin Infect Dis. 2006; 43:1329-1336. [PubMed: 17051502]

11. Petersen ML, van der Laan MJ, Napravnik S, Eron JJ, Moore RD, Deeks SG, et al. Long-term consequences of the delay between virologic failure of highly active antiretroviral therapy and regimen modification. AIDS. 2008; 22:2097-2106. [PubMed: 18832873]

12. Johnson BA, Ribaudo H, Gulick R, Eron J. Modeling clinical endpoints as a function of time of switch to second-line ART with incomplete data on switching times. Biometrics. 2013; 69:732740. [PubMed: 23862631]

13. Li L, Eron J, Ribaudo H, Gulick R, Johnson B. Evaluating the effect of early versus late ARV regimen change if failure on an initial regimen: results from the AIDS Clinical Trials Group study A5095. J Am Stat Assoc. 2012; 107:542-554. [PubMed: 23329858]

14. Laurent C, Kouanfack C, Laborde-Balen G, Aghokeng AF, Mbougua JB, Boyer S. Monitoring of HIV viral loads, CD4 cell counts, and clinical assessments versus clinical monitoring alone for antiretroviral therapy in rural district hospitals in Cameroon (Stratall ANRS 12110/ESTHER): a randomised non-inferiority trial. Lancet Infect Dis. 2011; 11:825-833. [PubMed: 21831714]

15. Chang LW, Harris JE, Humphreys E. Optimal monitoring strategies for guiding when to switch first-line antiretroviral therapy regimens for treatment failure in adults and adolescents living with HIV in low-resource settings. Cochrane Database Syst Rev. 2010:CD008494. [PubMed: 20393969]

16. Mermin J, Ekwaru J, Were W, Degerman R, Bunnell R, Kaharuza F, et al. Utility of routine viral load, CD4 cell count, and clinical monitoring among adults with HIV receiving antiretroviral therapy in Uganda: randomised trial. BMJ. 2011; 343:d6792. [PubMed: 22074711]

17. Saag, M.; Westfall, A.; Luhanga, D.; Mulenga, P.; Chi, B.; Mulenga, L., et al. A cluster randomized trial of routine vs discretionary viral load monitoring among adults starting ART: Zambia [Abstract \#87]. 19th Annual Conference on Retroviruses and Opportunistic Infections; 58 March 2012; Seattle, WA, USA.

18. Jourdain G, Le Cour S, Ngo-Giang-Huong N, Traisathit P, Cressey T, Fregonese F, et al. Switching HIV treatment in adults based on CD4 count versus viral load monitoring: a randomized, non-inferiority trial in Thailand. PLoS Med. 2013; 10:e1001494. [PubMed: 23940461]

19. Keiser O, Chi B, Gsponer T, Boulle A, Orrell C, Phiri S, et al. Outcomes of antiretroviral treatment in programmes with and without routine viral load monitoring in Southern Africa. AIDS. 2011; 25:1761-1769. [PubMed: 21681057]

20. ART-LINC of IeDEA Study Group. Switching to second-line antiretroviral therapy in resourcelimited settings: comparison of programmes with and without viral load monitoring. AIDS. 2009; 23:1867-1874. [PubMed: 19531928]

21. Levison JH, Orrell C, Losina E, Lu Z, Freedberg K, Wood R. Early outcomes and the virological effect of delayed treatment switching to second-line therapy in an antiretroviral roll-out programme in South Africa. Antivir Ther. 2011; 16:853-861. [PubMed: 21900717]

22. Robins JM, Hernan MA, Brumback B. Marginal structural models and causal inference in epidemiology. Epidemiology. 2000; 11:550-560. [PubMed: 10955408] 
23. Kalbfleisch, JD.; Prentice, RL. The statistical analysis of failure time data Wiley series in probability and statistics. Hoboken, NJ: Wiley Interscience; 2002.

24. Aalen O. Nonparametric estimation of partial transmission probabilities in multiple decrement models. Ann Stat. 1978; 6:534-545.

25. White $\mathrm{H}$. A heteroskedasticity-consistent covariance-matrix estimator and a direct test for heteroskedasticity. Econometrica. 1980; 48:817-838.

26. Gsponer T, Petersen M, Egger M, Phiri S, Maathuis M, Boulle A, et al. The causal effect of switching to second-line ART in programmes without access to routine viral load monitoring. AIDS. 2012; 26:57-65. [PubMed: 22089376]

27. Robins J. Association causation and marginal structural models. Synthese. 1999; 121:151-179.

28. van der Laan MJ, Polley EC, Hubbard AE. Super learner. Stat Appl Genet Mol Biol. 2007; 6 Article 25.

29. Kooperberg C, Bose S, Stone C. Polychotomous regression. J Am Stat Assoc. 1997; 92:117-127.

30. Kooperberg, C. [Accessed 3 June 2014] Polspline: Polynomial spline routines R package version 1.1.9. 2013. http://CRAN.R-project.org/package=polspline

31. Polley, EC.; van der Laan, M. [Accessed 3 June 2014] Super learner prediction R package version 2.0.9. 2012. http://CRAN.R-project.org/package=SuperLearner

32. Zhou J, Li P, Kumarasamy N, Boyd M, Chen Y, Sirisanthana T, et al. Deferred modification of antiretroviral regimen following documented treatment failure in Asia: results from the TREAT Asia HIV Observational Database (TAHOD). HIV Med. 2010; 11:31-39. [PubMed: 19601993]

33. Fox MP, Cutsem G, Giddy J, Maskew M, Keiser O, Prozesky H, et al. Rates and predictors of failure of first-line antiretroviral therapy and switch to second-line ART in South Africa. J Acquir Immune Defic Syndr. 2012; 60:428-437. [PubMed: 22433846]

34. Johnston V, Fielding KL, Charalambous S, Churchyard G, Phillips A, Grant AD, et al. Outcomes following virological failure and predictors of switching to second-line antiretroviral therapy in a South African treatment program. J Acquir Immune Defic Syndr. 2012; 61:370-380. [PubMed: 22820803]

35. Davies MA, Moultrie H, Eley B, Rabie H, Van Cutsem G, Giddy J, et al. Virologic failure and second-line antiretroviral therapy in children in South Africa - the IeDEA Southern Africa collaboration. J Acquir Immune Defic Syndr. 2011; 56:270-278. [PubMed: 21107266]

36. Havlir DV, Koelsch K, Strain M, Margot N, Lu B, Ignacio C, et al. Predictors of residual viremia in HIV-infected patients successfully treated with efavirenz and lamivudine plus either tenofovir or stavudine. J Infect Dis. 2005; 191:1164-1168. [PubMed: 15747253]

37. Gupta RK, Hill A, Sawyer A, Cozzi-Lepri A, von Wyl V, Yerly S, et al. Virological monitoring and resistance to first-line highly active antiretroviral therapy in adults infected with HIV-1 treated under WHO guidelines: a systematic review and meta-analysis. Lancet Infect Dis. 2009; 9:409_ 417. [PubMed: 19555900]

38. Geng EH, Glidden D, Bangsberg D, Bwana M, Musinguzi N, Nash D, et al. A causal framework for understanding the effect of losses to follow-up on epidemiologic analyses in clinic-based cohorts: the case of HIV-infected patients on antiretroviral therapy in Africa. Am J Epidemiol. 2012; 175:1080-1087. [PubMed: 22306557]

39. Hernan MA, Lanoy E, Costagliola D, Robins JM. Comparison of dynamic treatment regimes via inverse probability weighting. Basic Clin Pharmacol Toxicol. 2006; 98:237-242. [PubMed: 16611197]

40. van der Laan MJ, Petersen ML. Causal effect models for realistic individualized treatment and intention to treat rules. Int J Biostat. 2007; 3:3.

41. Wilson D, Keiluhu A, Kogrum S, Reid T, Seriratana N, Ford N, et al. HIV-1 viral load monitoring: an opportunity to reinforce treatment adherence in a resource-limited setting in Thailand. Trans $\mathrm{R}$ Soc Trop Med Hyg. 2009; 103:601-606. [PubMed: 19110288]

42. Sigaloff KC, Hamers RL, Wallis CL, Kityo C, Siwale M, Ive P, et al. Unnecessary antiretroviral treatment switches and accumulation of HIV resistance mutations; two arguments for viral load monitoring in Africa. J Acquir Immune Defic Syndr. 2011; 58:23-31. [PubMed: 21694603] 
43. Kantor R, Diero L, Delong A, Kamle L, Muyonga S, Mambo F, et al. Misclassification of first-line antiretroviral treatment failure based on immunological monitoring of HIV infection in resourcelimited settings. Clin Infect Dis. 2009; 49:454-462. [PubMed: 19569972]

44. Phillips AN, Pillay D, Garnett G, Bennett D, Vitoria M, Cambiano V, et al. Effect on transmission of HIV-1 resistance of timing of implementation of viral load monitoring to determine switches from first to second-line antiretroviral regimens in resource-limited settings. AIDS. 2011; 25:843850. [PubMed: 21192233]

45. Phillips AN, Pillay D, Miners A, Bennett D, Gilks C, Lundgren JD. Outcomes from monitoring of patients on antiretroviral therapy in resource-limited settings with viral load, CD4 cell count, or clinical observation alone: a computer simulation model. Lancet. 2008; 371:1443-1451. [PubMed: 18440426]

46. Kahn JG, Marseille E, Moore D, Bunnell R, Were W, Degerman R, et al. CD4 cell count and viral load monitoring in patients undergoing antiretroviral therapy in Uganda: cost effectiveness study. BMJ. 2011; 343:d6884. [PubMed: 22074713]

47. Bishai D, Colchero A, Durack DT. The cost effectiveness of antiretroviral treatment strategies in resource-limited settings. AIDS. 2007; 21:1333-1340. [PubMed: 17545710]

48. Braithwaite RS, Nucifora K, Yiannoutsos C, Musick B, Kimaiyo S, Diero L, et al. Alternative antiretroviral monitoring strategies for HIV-infected patients in east Africa: opportunities to save more lives? J Int AIDS Soc. 2011; 14:38. [PubMed: 21801434]

49. Estill J, Aubriere C, Egger M, Johnson L, Wood R, Garone D, et al. Viral load monitoring of antiretroviral therapy, cohort viral load and HIV transmission in Southern Africa: a mathematical modelling analysis. AIDS. 2012; 26:1403-1413. [PubMed: 22421243] 
(a)

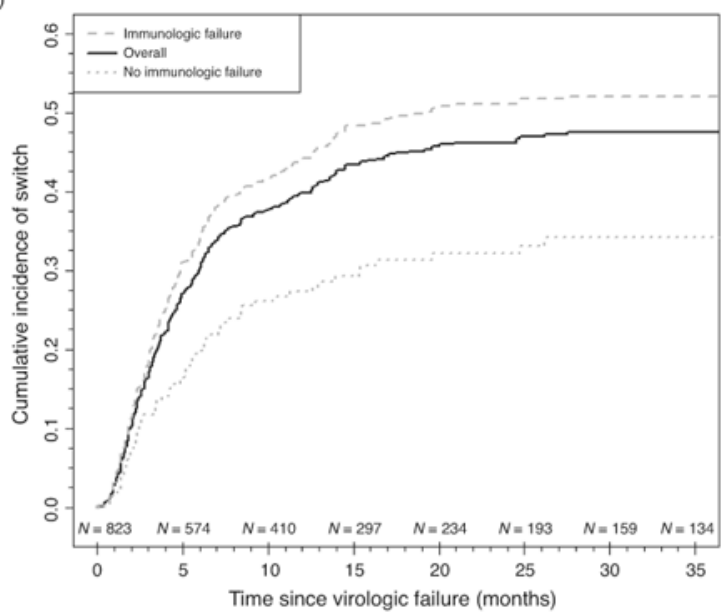

(b)

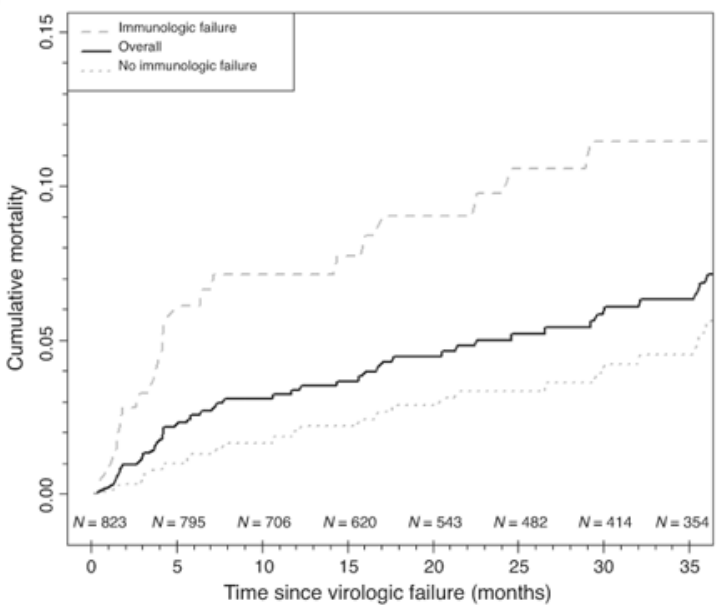

Fig. 1. Cumulative incidence of switch to second-line antiretroviral therapy (ART) (a) and mortality (b) following confirmed virologic failure on first-line NNRTI-based ART, among 823 patients with confirmed virologic failure, overall and stratified by WHO immunological failure at or before time of virologic failure

$N$ refers to full cohort (not stratified by immunologic failure). 
(a)

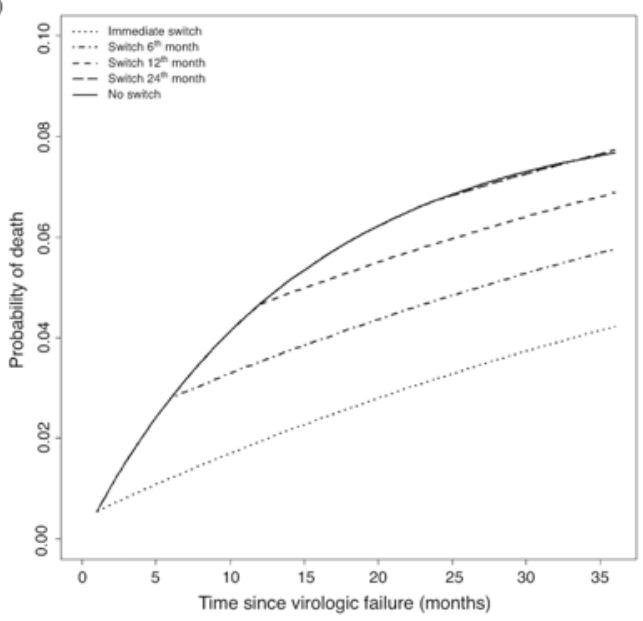

(b)

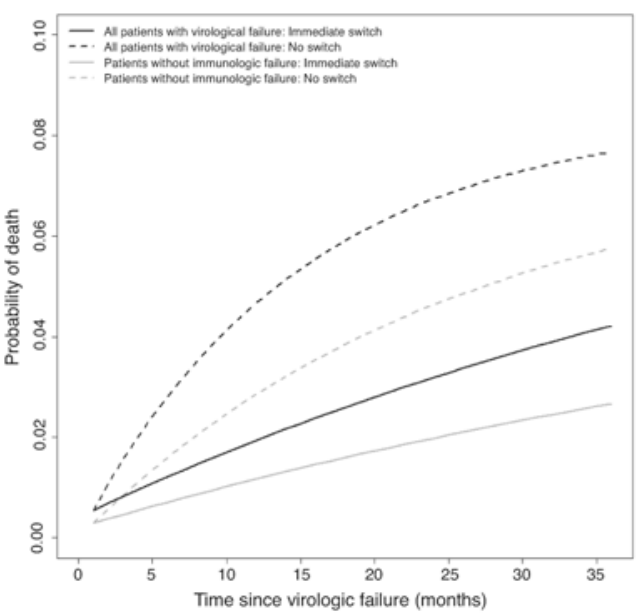

Fig. 2. Counterfactual mortality curves following confirmed virologic failure on first-line NNRTI-based ART, estimated using inverse probability weighting of marginal structural models (a) Among all patients with confirmed virological failure $(N=823)$ under a range of hypothetical delays before switching to second-line antiretroviral therapy, ranging from immediate switch (within 30 days of confirmed virologic failure) to never switch, (b) Among all patients with confirmed virological failure $(N=823)$ and only those patients without WHO immunological failure at or before time of virologic failure $(N=610)$, under immediate switch (within 30 days of confirmed virologic failure) and never switch. 


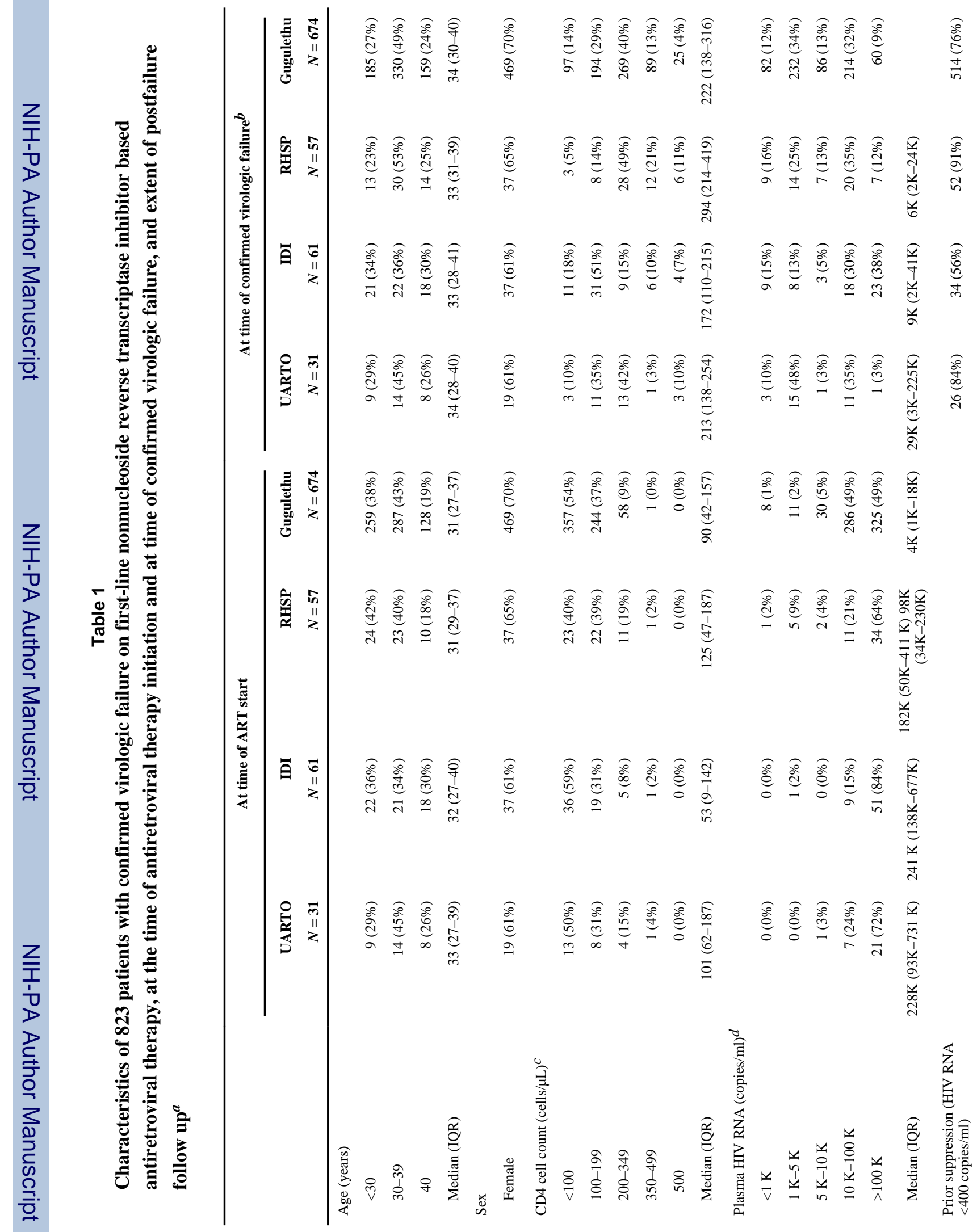


Petersen et al.

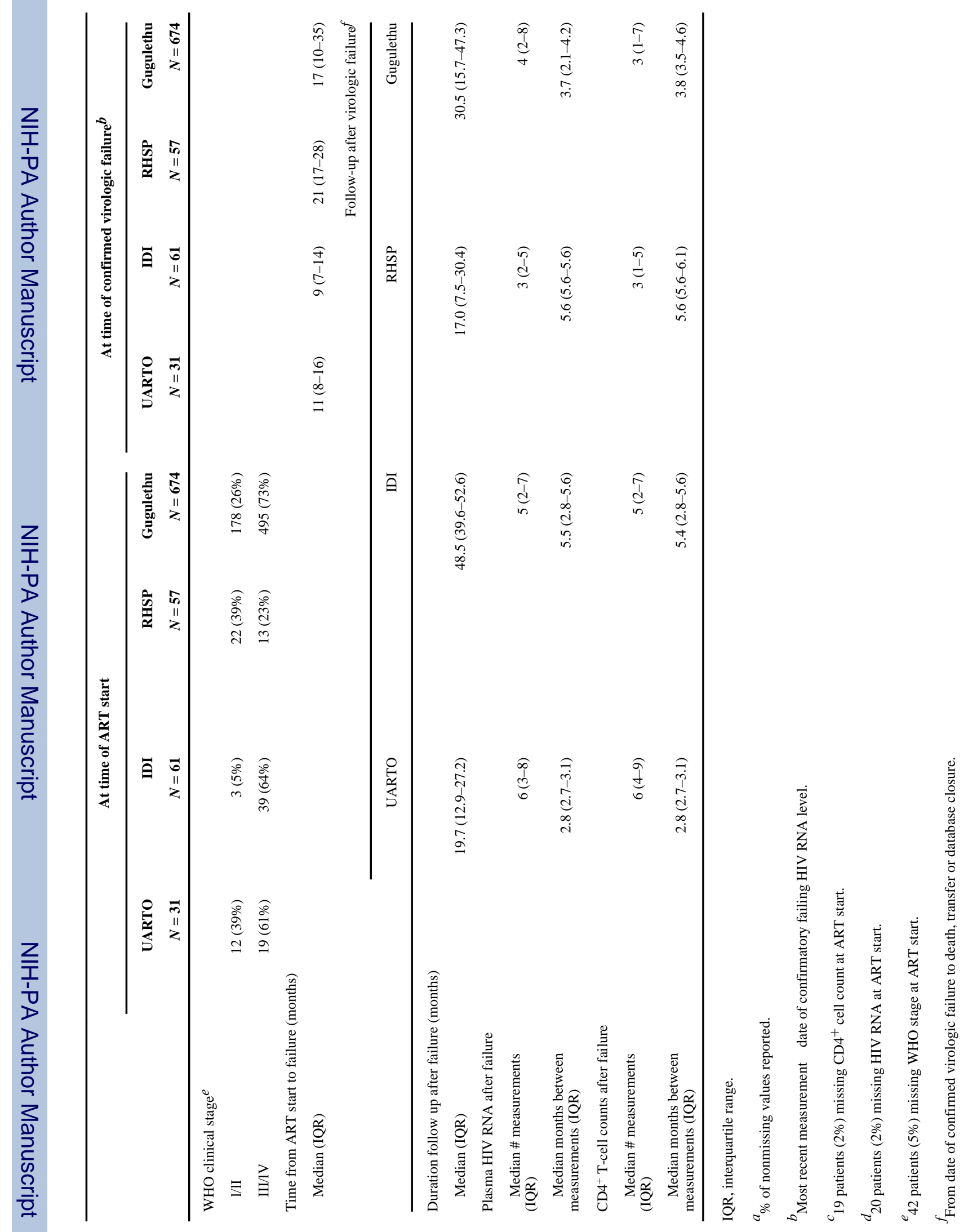

AIDS. Author manuscript; available in PMC 2015 February 04. 
Table 2

Unadjusted predictors of switch to second-line antiretroviral therapy and mortality ${ }^{a}$

\begin{tabular}{|c|c|c|}
\hline & Relative odds of switch (95\% CI) & Relative odds of death $(95 \% \mathrm{CI})$ \\
\hline Age (per 10 years) & $0.91(0.78-1.07)$ & $1.80 *(1.30-2.51)$ \\
\hline Male sex & $0.81(0.62-1.05)$ & $1.93 *(1.09-3.43)$ \\
\hline \multicolumn{3}{|l|}{$\mathrm{CD} 4^{+} \mathrm{T}$ cell count (per 100 cells $\left./ \mu \mathrm{l}\right)$} \\
\hline At ART start & $0.71 *(0.62-0.81)$ & $0.95(0.69-1.30)$ \\
\hline Nadir & $0.66^{*}(0.55-0.78)$ & $0.56^{*}(0.36-0.88)$ \\
\hline Peak & $0.88^{*}(0.83-0.94)$ & $0.87(0.73-1.05)$ \\
\hline At virologic failure & $0.95(0.87-1.04)$ & $0.77(0.56-1.06)$ \\
\hline Most recent measurement & $0.86^{*}(0.80-0.94)$ & $0.53 *(0.37-0.76)$ \\
\hline $\mathrm{CD}^{+}$cell count decline since failure (per $10 \%$ ) & $1.06^{*}(1.01-1.11)$ & $1.17^{*}(1.09-1.27)$ \\
\hline \multicolumn{3}{|l|}{ Plasma HIV RNA level (per log 10copies/ml) } \\
\hline At virologic failure & $1.11(0.98-1.26)$ & $1.78^{*}(1.22,-2.61)$ \\
\hline Peak & $0.94(0.76-1.15)$ & $2.79^{*}(1.71-4.57)$ \\
\hline Nadir & $1.13^{*}(1.03-1.24)$ & $1.41^{*}(1.04-1.91)$ \\
\hline Most recent measurement & $1.57^{*}(1.43-1.73)$ & $2.02 *(1.50-2.74)$ \\
\hline Suppression prior to failure $b$ & $0.86(0.66-1.12)$ & $1.00(0.53-1.88)$ \\
\hline \multicolumn{3}{|l|}{ WHO clinical stage at ART Start } \\
\hline Stage I/II & Ref & Ref \\
\hline Stage III/IV & $1.51^{*}(1.17-1.95)$ & $2.52(0.98-6.46)$ \\
\hline ART start to failure (per 180 days) & $0.91 *(0.87-0.96)$ & $1.01(0.91-1.13)$ \\
\hline Seen in prior 90-day interval & $0.89(0.71-1.11)$ & $1.82^{*}(1.02-3.27)$ \\
\hline Time since last recorded visit (per 180 days) & $0.87(0.66-1.15)$ & $0.68(0.46-1.02)$ \\
\hline
\end{tabular}

ART, antiretroviral therapy; CI, confidence interval.

* $\mathrm{P}<0.05$.

$a_{\text {In addition to the above variables, candidate predictors for estimated switching and censoring weights included: square root and categorical }}$ transformations of $\mathrm{CD} 4{ }^{+}$cell count values; categorical transformations of HIV RNA values; indicators of whether an HIV RNA or $\mathrm{CD}^{+}{ }^{+}$cell count test was performed in the previous 90-day interval; WHO immunologic failure criteria; time since failure; calendar date of failure; and clinic.

$b$ Defined as at least one HIV RNA $\leq 400$ copies/ml after starting ART and prior to confirmed failure. 
Table 3

Unadjusted and inverse probability weighted estimates of the association between switch to second-line therapy following confirmed virologic failure and mortality ${ }^{a}$

\begin{tabular}{|c|c|c|c|}
\hline Patient population/censoring definition & Main term model $b$ & $\begin{array}{l}\text { Model including } \\
\text { interaction with time } c\end{array}$ & \\
\hline \multirow{4}{*}{ Confirmed virologic failure $(N=823)^{g}$} & $\begin{array}{l}\text { Main term for switch status (OR } \\
\text { for mortality on first-line versus }\end{array}$ & \multirow{2}{*}{$\begin{array}{l}\text { Main term for switch } \\
\text { status } e(95 \% \mathrm{CI}) ; P \\
\text { value }\end{array}$} & $\begin{array}{l}\text { Interaction term between } \\
\text { switch status and time }\end{array}$ \\
\hline & $\begin{array}{l}\text { second-line therapy })^{d}(95 \% \mathrm{CI}) \\
P \text { value }\end{array}$ & & $\begin{array}{l}\text { since failure } f(95 \% \mathrm{CI}) \\
P \text { value }\end{array}$ \\
\hline & $\begin{array}{l}\text { Unadjusted: } 1.47(0.83-2.60) ; P= \\
0.19\end{array}$ & $\begin{array}{l}\text { Unadjusted: } 3.19(1.24- \\
8.20) ; P=0.016\end{array}$ & $\begin{array}{l}\text { Unadjusted: } 0.95(0.90- \\
1.00) ; P=0.068\end{array}$ \\
\hline & IPW: $2.12(1.09-4.15) ; P=0.027$ & $\begin{array}{l}\text { IPW: } 4.18(1.54-11.32) \\
P=0.005\end{array}$ & $\begin{array}{l}\text { IPW: } 0.95(0.90-1.01) ; P \\
=0.086\end{array}$ \\
\hline \multirow[t]{2}{*}{$\begin{array}{l}\text { Confirmed virologic failure }(N=823) \text {; censored } \\
\text { at } 9 \text { months without visit }{ }^{h}\end{array}$} & $\begin{array}{l}\text { Unadjusted: } 1.75(0.89-3.42) ; P= \\
0.10\end{array}$ & $\begin{array}{l}\text { Unadjusted: } 3.62(1.28- \\
10.19) ; P=0.015\end{array}$ & $\begin{array}{l}\text { Unadjusted: } 0.93(0.85- \\
1.01) ; P=0.090\end{array}$ \\
\hline & IPW: $2.46(1.17-5.17) ; P=0.017$ & $\begin{array}{l}\text { IPW: } 5.46(1.87-15.95) \\
P=0.002\end{array}$ & $\begin{array}{l}\text { IPW: } 0.91(0.82-1.02) ; P \\
=0.096\end{array}$ \\
\hline \multirow[t]{2}{*}{$\begin{array}{l}\text { Confirmed virologic failure without prior } \\
\text { immunologic failure }(N=610)^{i}\end{array}$} & $\begin{array}{l}\text { Unadjusted: } 1.31(0.63-2.72) ; P \\
=0.47\end{array}$ & $\begin{array}{l}\text { Unadjusted: } 2.60(0.82- \\
8.24) ; P=0.10\end{array}$ & $\begin{array}{l}\text { Unadjusted: } 0.96(0.91- \\
1.01) ; P=0.14\end{array}$ \\
\hline & IPW: $2.40(0.99-5.82) ; P=0.052$ & $\begin{array}{l}\text { IPW: } 3.43(0.99-11.88) \\
P=0.052\end{array}$ & $\begin{array}{l}\text { IPW: } 0.98(0.93-1.03) ; P \\
=0.40\end{array}$ \\
\hline \multirow[t]{2}{*}{$\begin{array}{l}\text { Confirmed virologic failure with prior viral } \\
\text { suppression }(N=626)^{j}\end{array}$} & $\begin{array}{l}\text { Unadjusted: } 1.19(0.63-2.26) ; P= \\
0.59\end{array}$ & $\begin{array}{l}\text { Unadjusted: } 3.13(1.12- \\
8.69) ; P=0.029\end{array}$ & $\begin{array}{l}\text { Unadjusted: } 0.93(0.86- \\
1.00) ; P=0.054\end{array}$ \\
\hline & IPW: $1.93(0.87-4.28) ; P=0.11$ & $\begin{array}{l}\text { IPW: } 4.24(1.42-12.63) \\
P=0.010\end{array}$ & $\begin{array}{l}\text { IPW: } 0.94(0.87-1.01) ; P \\
=0.094\end{array}$ \\
\hline \multirow[t]{2}{*}{ Nonconfirmed virologic rebound $(N=1337)^{k}$} & $\begin{array}{l}\text { Unadjusted: } 0.59(0.33-1.06) ; P= \\
0.078\end{array}$ & $\begin{array}{l}\text { Unadjusted: } 1.18(0.43- \\
3.25) ; P=0.76\end{array}$ & $\begin{array}{l}\text { Unadjusted: } 0.97(0.94- \\
1.01) ; P=0.087\end{array}$ \\
\hline & IPW: $0.96(0.44-2.08) ; P=0.92$ & $\begin{array}{l}\text { IPW: } 1.09(0.30-3.95) ; P \\
=0.89\end{array}$ & $\begin{array}{l}\text { IPW: } 0.99(0.95-1.04) ; P \\
=0.77\end{array}$ \\
\hline
\end{tabular}

CI, confidence interval; OR, odds ratio.

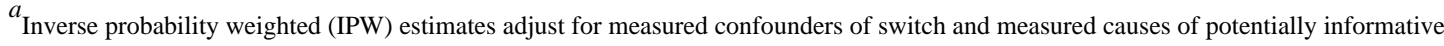
censoring using inverse probability weights.

${ }^{b} P\left(Y_{\text {Switch. time }}(t)=1 \mid Y_{\text {Switch. time }}(t-1)=0\right)=\exp i t\left(\beta_{0}+\beta_{1} \mid(\right.$ switch.time $\left.\geq t)+\beta_{2} t\right)$.

${ }^{c} P\left(Y_{\text {Switch }}\right.$ time $(t)=1 \mid Y_{\text {Switch. }}$ time $\left.(t-1)=0\right)=\exp i t\left(a_{0}+a_{1} \mid(\right.$ switch. time $\geq t)+a_{2} t+a_{3} \mid($ switch.time $\left.>t) \times t\right)$ : Corresponding mortality functions plotted in Figure 2.

$d \exp (\beta 1)$

$e \exp (\mathrm{a} 1)$

$f \exp (a 3)$.

${ }^{g}$ Follow-up until death, database closure or reported transfer. Mean weights $=0.93$; range: $0.02-10$.

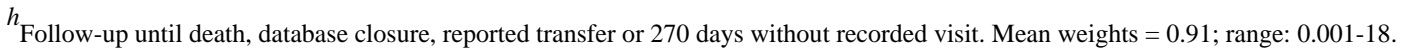

${ }^{i}$ Patients had not met any of WHO immunologic failure criteria at or before time of confirmed virologic failure. Follow up until death, database closure or reported transfer. Mean weights $=1.05$; range: $0.03-22$

${ }^{j}$ Patients with at least one HIV RNA level <400 copies/ml prior to confirmed virologic failure. Follow up until death, database closure, or reported transfer. Mean weights $=0.94$; range: $0.10-17$. 
${ }^{k}$ Nonconfirmed rebound defined as an HIV RNA level $\geq 400$ copies/ml, preceded by at least one HIV RNA level <400 copies/ml. Follow-up until death, database closure or reported transfer. Mean weights $=0.96$; range: $0.10-8$. 